\title{
TÁC ĐộNG CỦA ĐẠI DỊCH COVID-19 TỚI NHÂN VIÊN Y TÉ TẠI HÀ NỌI NĂM 2020
}

\author{
Lê Thị Thanh Xuân, Nguyễn Thanh Thảo, Phạm Thị Quân, \\ Tạ Thị Kim Nhung, Nguyễn Thị Quỳnh ${ }^{凶}$, Nguyễn Huy Hoàng, \\ Trần Thị Thùy Linh, Nguyễn Thị Vinh
}

Viện Đào tạo YHDP và YTCC, Trường Đại học Y Hà Nội

Nghiên cứu mô tả cắt ngang sử dụng bộ câu hỏi điều tra online trên 2157 đối tượng nhằm đánh giá tác động của đại dịch COVID-19 lên công việc và cuộc sống của cán bộ y tế tại Hà Nội bằng phương pháp phân tích nhân tố. Kết quả của nghiên cứu cho thấy đại dịch Covid 19 có ảnh hưởng đáng kể tới cuộc sống và công việc của nhân viên y tế trên địa bàn Hà Nội. Nhân viên y tế tuyến huyện/xã có nhiều áp lực trong công việc hơn tuyến trung ương (Coef: 0,104; 95\% Cl:0,059;0,148), điều dưỡng nhiều áp lực hơn bác sĩ (Coef: 0,5; 95\% Cl:0,0090,095). Người có tuổi đời, tuổi nghề càng cao thì áp lực công việc càng lớn nhưng lại có thái độ làm việc tích cực hơn. Người làm việc tại nơi có nguy cơ tiếp xúc thì có thái độ bi quan hơn những người làm việc ở nơi gần như không phải tiếp xúc với dịch bệnh COVID-19.

Từ khóa: tác động, nhân viên y tế, COVID-19, Hà Nội.

\section{I. ĐẠT VÂN ĐỀ}

Tính đến ngày 27/12/2020, tình hình COVID-19 có nhiều diễn biến phức tạp. Đại dịch đã lan sang 222 quốc gia và vùng lãnh thổ, báo cáo hơn 79 triệu trường hợp mắc và 1.751.311 trường hợp tử vong do vi rút SARS-CoV-2 gây nhiễm trùng đường hô hấp cấp COVID-19. Tại Việt Nam tính đến ngày 26 tháng 12 năm 2020, có 1440 trường hợp nhiễm COVID-19; 35 trường hợp tử vong. ${ }^{1}$

COVID-19 có tác động đáng kể đến sức khỏe cộng đồng và đặt ra thách thức cho nhân viên y tế, đặc biệt là nhân viên y tế tuyến đầu tiếp xúc trực tiếp với bệnh nhân COVID-19. Các nghiên cứu trên thế giới cho thấy đại dịch COVID-19 có thể ảnh hưởng đến tình trạng sức khỏe của nhân viên y tế do làm tăng tỷ lệ nhiễm COVID-19 và làm tăng tỷ lệ mất ngủ, mệt mỏi,

Tác giả liên hệ: Nguyễn Thị Quỳnh

Viện Đào tạo YHDP và YTCC, Trường Đại học Y Hà Nội

Email: nguyenthiquynhhmu@gmail.com

Ngày nhận: 01/04/2021

Ngày được chấp nhận: 22/07/2021 lo âu hoặc trầm cảm cho nhân viên y tế. . $3,4,5^{3}$ Vè những thách thức trong công việc, Schwartz et al chỉ ra rằng ở Trung Quốc, nỗi sợ bị lây nhiễm và áp lực liên quan đến công việc là động lực chính khiến một số nhân viên y tế tìm việc khác. ${ }^{6}$ Nhân viên y tế thừa nhận rằng họ cảm thấy bất an do thiếu phương tiện bảo vệ cá nhân (PPE) và cảm thấy bất lực khi điều trị cho những bệnh nhân nặng có tiên lượng xấu. ${ }^{7,8}$

Cho đến nay, các nghiên cứu tập trung vào tình hình dịch tễ học và đặc điểm lâm sàng của bệnh nhân mắc bệnh, ${ }^{9,} 10$ đặc điểm bộ gen của vi rút ${ }^{11}$ và những thách thức đối với quản lý $\mathrm{y}$ tế toàn cầu. ${ }^{12}$ Tuy nhiên, số nghiên cứu về tác động của COVID-19 đối với cuộc sống và công việc của nhân viên y tế tại Việt Nam còn hạn chế. Việt Nam ghi nhận ca nhiễm COVID-19 đầu tiên tại Hà Nội. ${ }^{13}$ Hà Nội là một trong những địa bàn có số ca nhiễm COVID-19 cao nhất Việt Nam. Việc tiến hành nghiên cứu nhằm phân tích tác động của COVID-19 tới công việc của nhân viên y tế tại Hà Nội là vô cùng cần thiết. Vì vậy chúng tôi thực hiện nghiên cứu này 
với mục tiêu: "Đánh giá tác động của đại dịch COVID-19 lên công việc của nhân viên y tế tại Hà Nội năm 2020" nhằm góp phần nâng cao hiệu suất làm việc và ngăn chặn sự lây lan của đại dịch COVID-19.

\section{II. ĐỐI TƯỢNG VÀ PHƯO'NG PHÁP}

\section{1. Đối tượng}

Nhân viên y tế đang làm việc tại các cơ sở y tế có nguy cơ cao tiếp xúc với bệnh nhân nhiễm COVID-19 trên địa bàn Hà Nội.

\section{Tiêu chuẩn lựa chọn}

Là cán bộ y tế trực tiếp và gián tiếp tham gia khám, điều trị và chăm sóc cho bệnh nhân hàng ngày tại các cơ sở y tế trên địa bàn Hà Nội, có thời gian công tác tại cơ sở y tế ít nhất 6 tháng trở lên và đồng ý tham gia vào nghiên cứu.

\section{Tiêu chí loại trùr}

Cán bộ y tế là người bệnh nhiễm COVID-19.

\section{Phương pháp}

\section{Thiết kế nghiên cứu}

Thiết cứu nghiên cứu mô tả cắt ngang.

\section{Địa điểm nghiên cứu}

Các cơ sở y tế trên địa bàn Hà Nội.

\section{Thò̀i gian nghiên cứru}

Từ tháng 3 năm 2020 tới tháng 12 năm 2020.

\section{Cõ̃ mẫu và chọn mẫu}

Cỡ mẫu thuận tiện: 2157 cán bộ y tế. Chọn đối tượng nghiên cứu là những cán bộ y tế tại các cơ sở y tế trên đại bàn Hà Nội có nguy cơ cao tiếp xúc với bệnh nhân nhiễm COVID-19. Bằng cách tiến hành lập danh sách các cơ sở y tế tham gia chống dịch COVID-19, sau đó gửi đường link bộ câu hỏi online cho các cán bộ $\mathrm{y}$ tế tại các cơ sở y tế trong danh sách. Trên thực tế có 2157 đối tượng tham gia nghiên cứu.

\section{Biến số và chỉ số nghiên cứu}

Biến số: tuyến cơ sở y tế, tuổi, giới, chuyên môn, đơn vị làm việc, số năm công tác, nguy cơ phơi nhiễm.

Chỉ số: thái độ lạc quan tại nơi làm việc và áp lực công việc được tính toán từ các biến số để đánh giá tác động của COVID-19 lên nhân viên y tế.

\section{Công cư và kỹ thuật thu thập dũ liệu}

Kỹ thuật thu thập dũ liệu: Lựa chọn đối tượng đủ tiêu chuẩn để tuyển chọn và loại trừ để phỏng vấn.Sử dụng bảng câu hỏi đã được xây dựng, chỉnh sửa, bổ sung để tạo bảng câu hỏi khảo sát. Gửi phiếu điều tra theo đường dẫn trực tuyến đã thiết kế sẵn đến tất cả các cơ sở y tế trên địa bàn Hà Nội theo danh sách đã lập.

Công cụ thu thập dũ liệu: bộ câu hỏi trực tuyến gồm hai phần.

Phần 1. Thông tin chung của đối tượng nghiên cứu: tuyến cơ sở y tế, tuổi, giới, chuyên môn, đơn vị làm việc, số năm công tác, nguy cơ phơi nhiễm.

Phần 2. Tác động của đại dịch COVID-19 lên cán bộ y tế: gồm những câu hỏi về thái độ tại nơi làm việc và áp lực công việc.

\section{Xử lí số liệu}

Số liệu được nhập và làm sạch bằng phần mềm Epidata 3.1 và STATA 14.0. Phân tích nhân tố khám phá được sử dụng để xác định các nhân tố từ các biến quan sát, hai nhân tố chính là "thái độ tại lạc quan tại nơi làm việc" và "áp lực công việc" được xác định, thống kê suy luận bằng các test thống kê đối với biến định tính là Khi bình phương ( $x 2)$, sử dụng mô hình hồi quy logistic đa biến nhằm xác định ảnh hưởng của COVID-19 đến nhân viên y tế trên địa bàn Hà Nội, năm 2020.

\section{4. Đạo đức nghiên cứu}

Tất cả đối tượng nghiên cứu đều được mời tham gia và thông báo về mục tiêu nghiên cứu. Các thông tin của đối tượng được giữ bí mật và chỉ sử dụng cho mục đích nghiên cứu. Đối tượng được toàn quyền quyết định tham gia và 
rời khỏi nghiên cứu. Nghiên cứu được Hội đồng phê duyệt của Viện Đào tạo Đào tạo $Y$ học dụ̣ phòng và $Y$ tế công cộng, Trường Đại học $Y$ Hà Nội phê duyệt vào tháng 3 năm 2020.

\section{KÉT QUẢ}

\section{1. Đặc điểm chung của đối tượng nghiên cứu}

Bảng 1. Đặc điểm nhân khẩu học của đối tượng nghiên cứu

\begin{tabular}{|c|c|c|c|}
\hline \multicolumn{2}{|c|}{ Đặc điểm (n = 2157) } & \multirow{2}{*}{$\begin{array}{c}\mathbf{n} \\
535\end{array}$} & \multirow{2}{*}{$\begin{array}{c}\% \\
24,8\end{array}$} \\
\hline & Trung ương & & \\
\hline \multirow[t]{2}{*}{ Tuyến bệnh viện } & Tỉnh & 178 & 8,3 \\
\hline & Huyện/xã & 1444 & 66,9 \\
\hline \multirow{2}{*}{ Giới tính } & Nam & 737 & 34,2 \\
\hline & Nũr & 1420 & 65,8 \\
\hline \multirow{4}{*}{ Chuyên môn } & Bác sĩ & 631 & 29,3 \\
\hline & Điều dưỡng & 990 & 45,9 \\
\hline & Kĩ thuật viên & 149 & 6,9 \\
\hline & Khác & 387 & 17,9 \\
\hline
\end{tabular}

Nghiên cứu được thực hiện trên 2157 cán hơn một nửa $(65,8 \%)$ đối tượng nghiên cứu. Về bộ y tế tại Hà Nội, công tác tại tuyến huyện/ chuyên môn điều dưỡng chiếm tỷ lệ cao nhất xã chiếm phần lớn với $66,9 \%$, nữ giới chiếm $\quad(45,9 \%)$, tiếp theo là bác sĩ $(29,3 \%)$.

2. Vị trí công tác của đối tượng nghiên cứu

Bảng 2. Vị trí công tác của đối tượng nghiên cứu

\begin{tabular}{lcc}
\hline \multicolumn{1}{c}{ Khoa } & $\mathbf{n}$ & $\%$ \\
\hline Cấp cứu/ Hồi sức tích cực & 173 & 8,0 \\
\hline Nội & 458 & 21,2 \\
\hline Ngoại - Sản - Nhi & 143 & 6,6 \\
\hline Chẩn đoán hình ảnh - Xét nghiệm & 69 & 3,2 \\
\hline Kiểm soát nhiễm khuẩn - truyền nhiễm/ kiểm soát bệnh lây & 548 & 25,4 \\
Kiểm soát bệnh tật và HIV/AIDS & 180 & 8,3 \\
\hline Hành chính & 586 & 27,2 \\
\hline Khác & Mean & SD \\
\hline & 36,32 & 8,60 \\
\hline Tuổi & 11,49 & 8,45 \\
\hline Tuổi nghề & & \\
\hline
\end{tabular}


Trong số cán bộ y tế tham gia nghiên cứu, tỷ lệ tại khoa cấp cứu, nôi, ngoại-sản-nhi tương đương nhau, lần lượt là 13,2\%; 13,6\%; 12,9\%; có đến $25,4 \%$ cán bộ y tế làm tại các khoa kiểm soát nhiễm khuẩn, truyền nhiễm, kiểm soát bệnh tât và HIVIAIDS tham gia vào nghiên cứu và $27,2 \%$ làm tại các khoa khác như dược, phục hồi chức năng. Tuổi trung bình của đối tượng nghiên cứu là $36,32 \pm 8,60$ tuổi và trung bình tuổi nghề là $11,49 \pm 8,45$ năm.

\section{Nguy cơ phơi nhiễm với COVID-19 của đối tượng nghiên cứu}

Bảng 3. Nguy cơ phơi nhiễm với COVID-19 của đối tượng nghiên cứu

\begin{tabular}{|c|c|c|}
\hline Nguy cơ phơi nhiễm & $\mathbf{n}$ & $\%$ \\
\hline Hàng ngày & 771 & 35,7 \\
\hline Thi thoảng & 1223 & 56,7 \\
\hline \multirow[t]{2}{*}{ Gần như không } & 163 & 7,6 \\
\hline & Mean & SD \\
\hline Tiếp xúc với ca chẩn đoán xác định & 0,41 & 7,14 \\
\hline Tiếp xúc với ca chưa chẩn đoán xác định & 3,02 & 45,43 \\
\hline
\end{tabular}

Trong tổng số đối tượng tham gia vào nghiên cứu có tới $35,7 \%$ là có nguy cơ phơi nhiễm với dịch bệnh hàng ngày, $56,7 \%$ là thi thoảng phơi nhiễm và chỉ có $7,6 \%$ là gần như không phơi nhiễm với COVID-19. Trung bình mỗi cán bộ y tế tiếp xúc với $0,41 \pm 7,14$ ca đã được chẩn đoán xác định, 3,02 $\pm 45,43$ ca chưa được chẩn đoán xác định.

\section{Tác động của dịch COVID-19 lên cuộc sống của nhân viên y tế Hà Nội năm 2020}

Bảng 4. Tác động của dịch COVID-19 lên cuộc sống của nhân viên y tế Hà Nội năm 2020

\begin{tabular}{lcc}
\hline \multicolumn{1}{c}{ Item } & $\begin{array}{c}\text { Thái độ lạc quan } \\
\text { tại nời làm việc }\end{array}$ & Áp lực công việc \\
\hline Bản thân được bệnh viện/khoa/lãnh đạo đánh giá cao & 0,558 \\
\hline Tinh thần làm việc tốt & 0,544 & \\
\hline Bản thân được xã hội đánh giá cao & 0,504 & \\
\hline Khối lượng công việc nhiều hơn & & 0,540 \\
\hline Phải làm thêm giờ & & 0,524 \\
\hline Phải làm công việc bình thường không phải làm & 0,797 & 0,516 \\
\hline Cronbach's alpha & 3,60 & 0,821 \\
\hline Mean & 0,49 & 3,04 \\
\hline SD & & 0,22 \\
\hline
\end{tabular}


Bảng 4. mô tả mô hình chuẩn hóa của bảng câu hỏi về sự tác động của COVID-19 lên cuộc sống và công việc của nhân viên y tế tại Hà Nội. Hai nhóm nhân tố "Thái độ lạc quan tại nơi làm việc" và "Áp lực công việc" với các biến thỏa mãn được thống kê trong bảng được phân tích từ EFA. Độ tin cậy của ba lĩnh vực là tốt với Cronbach's alpha giá trị lần lượt là 0,797 và 0,821 .

5. Các yếu tố liên quan đến tác động của COVID-19 lên công việc và cuộc sống của đối tượng nghiên cứu

Bảng 5. Bảng hồi quy các yếu tố liên quan đến tác động của COVID-19 lên công việc và cuộc sống của đối tượng nghiên cứu

\begin{tabular}{|c|c|c|c|c|c|}
\hline \multicolumn{2}{|c|}{ Đặc điểm } & \multicolumn{2}{|c|}{$\begin{array}{l}\text { Thái độ lạc quan } \\
\text { tại nơi làm việc }\end{array}$} & \multicolumn{2}{|c|}{ Áp lực công việc } \\
\hline \multirow{2}{*}{$\begin{array}{l}\text { Tuyến bệnh viện } \\
\text { (với Trung ương) }\end{array}$} & Tỉnh & Coef.: & $95 \% \mathrm{Cl}$ & Coef. & $95 \% \mathrm{Cl}$ \\
\hline & Huyện/xã & & & $0,104^{*}$ & 0,$059 ; 0,148$ \\
\hline $\begin{array}{l}\text { Giới tính } \\
\text { (với nam) }\end{array}$ & Nữ & $-0,59^{*}$ & $-0,1 ;-0,011$ & $-0,057^{*}$ & $-0,104 ;-0,013$ \\
\hline $\begin{array}{l}\text { Chuyên môn } \\
\text { (với bác sĩ) }\end{array}$ & Điều dưỡng & & & $0,5^{*}$ & $0,009-0,095$ \\
\hline \multirow{2}{*}{$\begin{array}{c}\text { Nguy co’ } \\
\text { (với hiếm khi) }\end{array}$} & Hàng ngày & $-0,91^{*}$ & $-0,132 ;-0,051$ & $-0,144^{*}$ & $-0,182 ;-0,101$ \\
\hline & Thi thoảng & $-0,097^{*}$ & 0,$055 ; 0,14$ & $0,129^{*}$ & 0,$088 ; 0,167$ \\
\hline \multicolumn{2}{|c|}{ Tuổi (năm) } & $0,1^{*}$ & $0,059-0,144$ & $0,119^{*}$ & $0,076-0,163$ \\
\hline \multicolumn{2}{|c|}{ Thâm niên (năm) } & $0,099^{*}$ & $0,056-0,142$ & $0,078^{*}$ & $0,036-0,124$ \\
\hline \multicolumn{6}{|c|}{${ }^{*} p<0,05$} \\
\hline
\end{tabular}

Bảng hồi quy logistic đa biến cho thấy nam giới có thái độ lạc quan với công việc hơn nữ giới, người gần như không tiếp xúc với COVID-19 suy nghĩ lạc quan hơn người phải tiếp xúc với dịch bệnh. Cán bộ tuyến huyện xã chịu áp lực công việc nhiều hơn tuyến trung ương, nam giới nhiều hơn nữ giới, người tiếp có nguy cơ phơi nhiễm với COVID-19 chịu áp lực nhiều hơn người không phải phơi nhiễm. Tuổi đời và thâm niên công tác càng cao thì thái độ tại nơi làm việc càng tích cực, áp lực công việc càng nhiều.

\section{BÀN LUẬN}

Đại dịch COVID-19 đang diễn biến phúc tạp và ảnh hưởng sâu rộng đến tất cả quốc gia trên thế giới. Nhân viên y tế là những người tiên phong trong công tác chống dịch, có nguy cơ lây nhiễm cao nhất, luôn phải làm việc quá giờ trong điều kiện thiếu các trang thiết bị bảo hộ cá nhân. Nghiên cứu nhằm tìm hiểu tác động của COVID-19 lên công việc họ bằng bộ câu hỏi điều tra online để đưa ra những khuyến nghị phù hợp giúp các nhà quản lý có giải pháp nâng cao chất lượng công việc cho cán bộ nhân viên y tế. Kết quả nghiên cứu của chúng tôi cho thấy hầu hết nhân viên y tế tại Hà Nội đều có nguy cơ phơi nhiễm với dịch bệnh, nam giới có thái độ lạc quan tại nơi làm việc hơn nữ giới. Cán bộ tuyến huyện xã chịu áp lực công việc nhiều 
hơn tuyến trung ương, nam giới nhiều hơn nũ giới, người tiếp có nguy cơ phơi nhiễm với COVID-19 chịu áp lực nhiều hơn người không phải phơi nhiễm. Tuổi đời và thâm niên công tác càng cao thì thái độ tại nơi làm việc càng lạc quan, áp lực công việc càng nhiều.

Nghiên cứu của chúng tôi tập trung đánh giá tác động của đại dịch COVID-19 lên công việc qua hai nhân tố là "thái độ lạc quan tại nơi làm việc" và "áp lực công việc". Nghiên cứu chỉ ra rằng nhân viên y tế tuyến huyện/ xã có thể có nhiều áp lực trong công việc hơn tuyến trung ương (Coef: 0,104; 95\% Cl:0,059 - 0,148), điều này có thể do tuyến cơ sở tiếp xúc gần dân hơn và trực tiếp phải đảm nhiệm những công việc như truy vết đối tượng nghi nhiễm, phun thuốc khử trùng, chăm sóc đối tượng cách ly. Kết quả cũng chỉ ra rằng mặc dù nữ giới có áp lực công việc thấp hơn (Coef: $-0,057 ; 95 \% \mathrm{Cl}$ : -0.104;-0.013) nhưng lại bi quan hơn nam giới (Coef: $-0,59 ; 95 \% \mathrm{Cl}:-0.1 ;-0.011$ ), kết quả này tương đồng với nghiên cứu của Mbachu và cộng sự về thái độ với COVID-19 của nhân viên y tế. ${ }^{14}$ Kết quả này có thể là do đặc điểm tâm sinh lý của nữ thường nhạy cảm và suy nghĩ nhiều hơn nam giới. Điều dưỡng cảm thấy nhiều áp lực công việc hơn bác sĩ (Coef: 0,5; 95\% Cl:0.009-0.095) tương đồng với kết quả của Esmail Shoja và cộng sự, ${ }^{15}$ là do họ là người trực tiếp chăm sóc bệnh nhân tại bệnh phòng nhiều hơn, thực hiện các thao tác gần với bệnh nhân hơn bác sĩ. Kết quả cũng chỉ ra rằng nhân viên y tế có nguy cơ phơi nhiễm với dịch bệnh thì bi quan hơn do họ có nguy cơ lây nhiễm dịch bệnh cao hơn, phải sống cách ly với người thân nhiều hơn những nhân viên y tế làm việc ở những nơi gần như không phải tiếp xúc với dịch COVID-19. Người có tuổi đời càng cao áp lực công việc càng lớn (Coef: 0,119; 95\% Cl: 0.076-0.163) nhưng lại lạc quan hơn (Coef: 0,1; 95\%Cl: 0.059-0.144). Kết quả tương tự, nhân viên y tế có tuổi nghề càng lâu áp lực công việc càng lớn (Coef: 0,078; 95\% Cl:0.036-0.124) nhưng lại có thái độ lạc quan hơn (Coef: 0,099; 95\%Cl:0.056-0.142) tương đồng với nghiên cứu của Esmail Shoja và cộng sự về áp lực của nhân viên y tế theo tuổi đời và tuổi nghề. ${ }^{15}$ Các kết quả có thể giải thích vì khi tuổi đời, tuổi nghề càng cao thì họ có nhiều kinh nghiệm hơn, ở vị trí cao hơn, đảm nhiệm nhiều công việc nên trách nhiệm sẽ cao hơn.

Đại dịch COVID-19 đang ngày càng lan rộng trên toàn thế giới, tác động đến mọi đối tượng, mọi mặt của xã hội. Nhân viên y tế là lực lượng có vai trò chủ đạo trong việc phòng ngừa và điều trị trong cuộc chiến này. Thực tế họ đang phải chịu rất nhiều áp lực về tâm lý và sức lực, áp lực công việc ngày càng lớn, kết quả của nghiên cứu phản ánh chi tiết hơn áp lực công việc của nhân viên y tế góp phần xây dựng chính sách hỗ trợ về tài chính, trang thiết bị bảo hộ, tâm lý để họ có đủ sức khỏe, tinh thần làm việc. Từ những kết quả của nghiên cứu, những nhà quản lý có thể có những biệp pháp thiết thực, đầy đủ hơn cho những đối tượng chịu tác động nhiều hơn như nhân viên tuyến cơ sở, điều dưỡng, nữ giới và những đối tượng có nguy cơ phơi nhiễm.

Tuy nhiên, nghiên cứu của chúng tôi còn một số hạn chế do là nghiên cứu mô tả cắt ngang nên chỉ có thể đánh giá tác động tại một thời điểm mà không đánh giá được lâu dài. Ngoài ra nghiên cứu sử dụng bộ câu hỏi trực tuyến nên có sai số do không quản lý được triệt để các đối tượng nghiên cứu, khó tiếp cận với những đối tượng không sử dụng thành thạo internet và điện thoại thông minh. Do đó cần có thêm những nghiên cứu sâu để đánh giá tác động lâu dài lên công việc của nhân viên y tế để có những biện pháp can thiệp cần thiết và kịp thời trong đại dịch COVID-19. 


\section{KÉT LUẦN}

COVID-19 gây ảnh hưởng lớn đến công việc và cuộc sống của nhân viên y tế tại Hà Nội, nam giới có thái độ lạc quan với công việc hơn nữ giới, người gần như không tiếp xúc với COVID-19 suy nghĩ lạc quan hơn người phải tiếp xúc với dịch bệnh. Cán bộ tuyến huyện xã chịu áp lực công việc nhiều hơn tuyến trung ương, nam giới nhiều hơn nữ giới, người tiếp có nguy cơ phơi nhiễm với COVID-19 chịu áp lực nhiều hơn người không phải phơi nhiễm. Tuổi đời và thâm niên công tác càng cao thì thái độ tại nơi làm việc càng tích cực, áp lực công việc càng nhiều.

\section{TÀI LIẸU THAM KHẢO}

1. WHO. Coronavirus Disease (COVID-19) Dashboard, truy cập ngày 26/12/2020, https:// covid19.who.int/

2. Huang JZ, Han MF, Luo TD, et al. [Mental health survey of medical staff in a tertiary infectious disease hospital for COVID-19]. Zhonghua lao dong wei sheng zhi ye bing za zhi = Zhonghua laodong weisheng zhiyebing zazhi = Chinese journal of industrial hygiene and occupational diseases. Mar 20 2020;38(3):192-195. doi:10.3760/ cma.j.cn121094-20200219-00063.

3. Lima CKT, Carvalho PMM, Lima I, et al. The emotional impact of Coronavirus 2019nCoV (new Coronavirus disease). Psychiatry research. May 2020;287:112915. doi:10.1016/j. psychres.2020.112915.

4. Lai J, Ma S, Wang $\mathrm{Y}$, et al. Factors Associated With Mental Health Outcomes Among Health Care Workers Exposed to Coronavirus Disease 2019. JAMA Netw Open. Mar 2 2020;3(3):e203976. doi:10.1001/ jamanetworkopen.2020.3976.

5. CI A. The World Factbook - Vietnam: Central Intelligence Agency (2020) 30/04/2020 2020.
6. Schwartz J, King CC, Yen MY. Protecting Healthcare Workers During the Coronavirus Disease 2019 (COVID-19) Outbreak: Lessons From Taiwan's Severe Acute Respiratory Syndrome Response. Clinical infectious diseases: an official publication of the Infectious Diseases Society of America. Jul 28 2020;71(15):858-860. doi:10.1093/cid/ ciaa255.

7. Anderson M, McKee M, Mossialos E. Covid-19 exposes weaknesses in European response to outbreaks. BMJ (Clinical research ed). Mar 18 2020;368:m1075. doi:10.1136/bmj. m1075.

8. Chen $\mathrm{Q}$, Liang $\mathrm{M}, \mathrm{Li} \mathrm{Y}$, et al. Mental health care for medical staff in China during the COVID-19 outbreak. Lancet Psychiatry. Apr 2020;7(4):e15-e16. doi:10.1016/s22150366(20)30078-x.

9. Huang C WY, Li X, et al. Clinical features of patients infected with 2019 novel coronavirus in Wuhan, China. THE LANCET 24/01/2020 2020;doi:https://doi.org/10.1016/S01406736(20)30183-5.

10. Chen N ZM, Dong $X$, et al. Epidemiological and clinical characteristics of 99 cases of 2019 novel coronavirus pneumonia in Wuhan, China: a descriptive study. THE LANCET. 30/01/2020 2020; doi: https://doi. org/10.1016/S0140-6736(20)30211-7.

11. Poujian Lu M, Xiang Zhao M, Juan Li P, et al. Genomic characterisation and epidemiology of 2019 novel coronavirus: implications for virus origins and receptor binding. Lancet (London, England). 30/01/2020 2020; doi:https://doi. org/10.1016/S0140-6736(20)30251-8.

12. Rubin GJ, Wessely S. The psychological effects of quarantining a city. BMJ 2020; 368: m313. doi:10.1136/bmj.m313 \%J BMJ. 
13. Nam BYTV. Bộ Y tế thông tin chính thức về ca nhiễm COVID-19 đầu tiên ở Hà Nội Bo $Y$ Te - Trang tin ve dich benh viem duong ho hap cap do Covid-19. 07/03/2020 2020;

14.Mbachu CN, Azubuike CM, Mbachu II, et al. COVID-19 infection: Knowledge, attitude, practices, and impact among healthcare workers in a South-Eastern Nigerian state.
Journal of infection in developing countries. Sep 30 2020;14(9):943-952. doi:10.3855/ jidc. 13248.

15.Shoja E, Aghamohammadi V, Bazyar H, et al. Covid-19 effects on the workload of Iranian healthcare workers. Nov 2 2020;20(1):1636. doi:10.1186/s12889-020-09743-w.

\section{Summary}

\section{IMPACT OF COVID-19 ON THE WORK AND PERSONAL LIFE OF HEALTHCARE WORKERS IN HANOI, 2020}

Online questionnaires were administered to 2157 healthcare wokers and professionals in Hanoi in 2020 to evaluate the impact of the COVID-19 pandemic on their work and personal life. Health workers at district/commune facilities had more pressure at work than those at national hospitals (Coef: $0.14 ; 95 \% \mathrm{Cl}$ : $0.059 ; 0.148)$. Nurses were more likely to experience work pressure than doctors. (Coef: 0.5; 95\% Cl: 0.009-0.095). The higher years in age and employment, the greater the work pressure, but also the more optimistic working attitude. Workers in areas at high risk of exposure to COVID-19 were more pessimistic than those who were areas with little risk of exposure.

Keyworks: impact on work, healthcare workers, COVID-19, Hanoi. 